\title{
Reflexión en torno a la reforma del Estado
}

\author{
$M^{\mathrm{a}}$ José Bobes Sánchez \\ Profesora Titular Interina. Universidad Complutense \\ mariajosebobes@der.ucm.es
}

Las causas de la crisis económica han sido profusamente expuestas desde distintas perspectivas y una vez confirmados los peores pronósticos que, para unos Estados más que para otros, tendría la aplicación de la Política Económica y Monetaria en ausencia de una zona monetaria óptima, se intentan diseñar y analizar las herramientas jurídicas con las que se tendría que dotar la Unión Europea y sus Estados Miembros para evitar o en su caso afrontar situaciones semejantes.

Sin embargo, la inaplicación de las reglas jurídicas a lo largo de todo este proceso se constata cada vez que se adoptan nuevas medidas que resultan además altamente controvertidas no sólo por los contenidos que disponen sino también por los sujetos que las adoptan y por los procedimientos que utilizan o por los que evitan. Por todo ello, la amenaza que representan para el Estado Social, los problemas de falta de legitimación democrática en la adopción de dichas decisiones que esta crisis ha vuelto a subrayar, la nueva relación que se dibuja entre Estado y Sociedad o el papel que le corresponde al Derecho en unos tiempos dominados por la Economía y la Política, son las grandes cuestiones tratadas en las ponencias del seminario y en las intervenciones habidas en el debate posterior a las que aquí sólo se añadirán algunos interrogantes surgidos con motivo de aquellas reflexiones.

La estabilidad del sistema financiero ha sido el interés público mayoritariamente invocado en las sucesivas reformas que se han incorporado en los últimos años a nuestro ordenamiento jurídico que han alcanzado, como es sabido, a la Constitución con la reforma de su art. 135. Dicho interés, si bien en cuanto estabilidad financiera del euro, está presente también en las diversas normas y modificaciones aprobadas en el seno de la Unión Europea con motivo de la crisis económica que también han afectado al Derecho originario, en concreto, al art. 136 TFUE que, en su nueva redacción, dispone asistencia financiera, en determinados supuestos y sujeta a estrictas condiciones, para los Estados cuya moneda es el euro.

Hasta el momento, los tribunales han dictaminado generalmente la conformidad a Derecho de estas medidas ante la realidad de la situación económica. Así, por ejemplo, no han visto obstáculos a la celebración de Tratados Internacionales entre miembros de la Unión Europea que situándose al margen del Derecho Comunitario, entregan no obstante competencias a sus instituciones o se interpretan en función del Derecho originario. El Tribunal de Justicia de la Unión Europea, ha confirmado las decisiones adoptadas ante la crisis económica de las que ha conocido como en el caso del establecimiento del MEDE. Incluso el Tribunal Constitucional Federal Alemán, pese a su lenguaje wagneriano, ha acompañado todos los pasos dados por la Unión Europea desde su resolución sobre la ayuda a Grecia en el inicio de la crisis ( y ya antes) hasta el papel del Banco Central Europeo respecto a la compra de deuda pública, recaída tan sólo hace unas semanas. Y es que, si bien, en esta última se manifiesta contrario a dicha posibilidad, interpone una cuestión prejudicial al TJUE al que somete la decisión no sin olvidar indicarle las condiciones por las que la consideraría permitida. Descendiendo un escalón y situándonos en nuestro Derecho interno, es posible comprobar cómo también los tribunales ordinarios o constitucionales acuden con frecuencia a dicha justificación para defender la conformidad a Derecho de determinadas medidas o del empleo de procedimientos justificados en razones de urgencia. La situación económica está siendo, por ejemplo, un argumento de peso en la jurisprudencia contencioso-administrativa para legitimar las últimas modificaciones aprobadas en materia de energía eléctrica que podrían contravenir principios fundamentales del Estado de Derecho, como la seguridad jurídica o el de confianza legítima; mientras que la generosa jurisprudencia constitucional respecto al empleo del Decreto-Ley para adoptar medidas económicas ha permitido que se haya convertido en la forma común de trans- 
posición de normas europeas si atendemos a muchos de los Preámbulos de los dictados en los últimos años.

En otro orden, la contención del déficit público y la limitación de las posibilidades de endeudamiento de las Administraciones Públicas motivadas con motivo del necesario cumplimiento de los requisitos de convergencia para entrar en la entonces ansiada tercera fase de la Unión Económica y Monetaria, produjo una fascinación por la privatización de la financiación que vio en el recurso al mercado una solución inagotable. Demostrados los riesgos de esta opción, se observan sin embargo decisiones públicas que pueden parecer contradictorias. Si la reforma constitucional, acordada en realidad en la Unión Europea, parece tener como objetivo poner coto a la dependencia estatal del crédito, exigiéndole contención en su recurso constante a los mercados, las medidas arbitradas, también por dichas instancias, para auxiliar a los Estados Miembros en apuros, consisten en facilitarles aunque indirectamente financiación que igualmente proviene de los mercados. El interés público que se afirma estar detrás de la necesaria estabilidad del sistema financiero queda al menos un poco desdibujado.

Que el Derecho necesita nuevos principios, normas y procedimientos parece algo hoy ya incuestionable. Pero también se puede dudar de si los ya habilitados por el Estado de Derecho resultan inservibles, han sido sencillamente inaplicados o, como en el caso del interés público y el privado, confundidos. 